André Planting - Siang Kho - Maria van der Burg

Hoo Goey · Jan Schellens · Martin van den Bent

Ate van der Gaast · Maureen de Boer-Dennert

Gerrit Stoter · Jaap Verweij

\title{
A phase II study of weekly high-dose cisplatin combined with oral etoposide in advanced non-small-cell lung cancer
}

Received: 25 August 1996 / Accepted: 20 January 1997

\begin{abstract}
As a dose-response relationship has been suggested for cisplatin, it appeared attractive to explore highdose-intensity regimens in non-small-cell lung cancer. In a phase I study of weekly administration of cisplatin combined with oral etoposide we achieved a cisplatin dose intensity of $52.5-60 \mathrm{mg} / \mathrm{m}^{2}$ per week in most patients. We subsequently explored this regimen in advanced non-smallcell lung cancer. Patients were treated with cisplatin infused at $70 \mathrm{mg} / \mathrm{m}^{2}$ on days $1,8,15$ and $29,36,43$ in combination with oral etoposide given at $50 \mathrm{mg}$ on days $1-15$ and 29-43. Patients showing stable disease or a better response were continued on treatment with oral etoposide given at $50 \mathrm{mg} / \mathrm{m}^{2}$ per day on days $1-21$ every 28 days for a maximum of four cycles. In all, 22 patients with stage III disease and 31 patients with stage IV disease entered the study. The median number of cisplatin administration was 6 per patient; 17 patients reached the planned cisplatin dose intensity of $60 \mathrm{mg} / \mathrm{m}^{2}$ per week, 11 patients achieved $52.5 \mathrm{mg} / \mathrm{m}^{2}$ per week, and 7 patients reached $47 \mathrm{mg} / \mathrm{m}^{2}$ per week. Overall, 11 of 21 stage III patients had a partial response [response rate $51 \%, 95 \%$ confidence interval (CI) $36-81 \%$ ], as did 9 of 28 patients with stage IV disease (32\%; 95\% CI 15-49\%). Toxicity was mainly hematologic,
\end{abstract}

This study was supported by Dutch Cancer Foundation grant CKVO91/15

A. Planting ( ) M. van der Burg • H. Goey • J. Schellens • M. de Boer - A. van der Gaast - G. Stoter - J. Verweij

Department of Medical Oncology, Rotterdam Cancer Institute/

University Hospital Rotterdam, P.O. Box 5201, 3008 AE Rotterdam,

The Netherlands

Tel.: +31-10-4391733

Fax: 31-10-4851618

S. Kho

Department of Pulmonology, University Hospital Rotterdam, dr. Molewaterplein 40, 3015 GD Rotterdam, The Netherlands

M. van den Bent

Department of Neuro-Oncology, Rotterdam Cancer Institute/University Hospital Rotterdam, Groene Hilledijk 301, 3075 EA Rotterdam,

The Netherlands with leukocytopenia being the most frequent cause of treatment delay. Nephrotoxicity of grade 1 was observed in seven patients. Two patients developed clinical hearing loss. With this schedule a high median cisplatin dose intensity of $52.5-60 \mathrm{mg} / \mathrm{m}^{2}$ per week was reached. The $51 \%$ response rate achieved in stage III disease makes this schedule attractive for further exploration; however, it is not recommended for routine use in stage IV disease.

Key words: Non-small-cell lung cancer - Cisplatin • Oral etoposide $\cdot$ Dose intensity

\section{Introduction}

The prognosis for patients with locally advanced or metastatic non-small-cell lung cancer (NSCLC) remains poor in spite of the continuous exploration of new cytotoxic drugs and the introduction of combined modality regimens. The impact of cisplatin-containing chemotherapy on survival is modest [29, 36, 38]. The meta-analysis of Donnadieu et al. [9] has shown that the response rate obtained with combinations of cisplatin with podophyllotoxins, vinca alkaloids, or ifosfamide and mitomycin C averages $34 \%$ in stage III disease but only $22 \%$ in metastatic disease. The combination of cisplatin and etoposide is widely used in NSCLC. Both drugs have only limited single-agent activity, with response rates varying from $8 \%$ to $30 \%[1-4,7,10,11,28$, $32,35,40]$. The combination is suggested to be synergistic in cell lines as well as clinically $[25,37]$. The activity and side effects of commonly applied schedules of this combination have been extensively described [22].

In several tumor types a relationship has been suggested between the cisplatin dose intensity and the response rate or response duration [12, 13, 16, 31]. However, the results of prospective randomized studies addressing the issue of cisplatin dose intensity in NSCLC have not been conclusive $[14,16,23]$. The highest cisplatin dose intensity reached in these studies was $41 \mathrm{mg} / \mathrm{m}^{2}$ per week [14]. 
In a phase I study exploring weekly administration of cisplatin combined with oral etoposide, we reached a higher median cisplatin dose intensity of $52.5 \mathrm{mg} / \mathrm{m}^{2}$ per week [33]. In this schedule we made use of oral etoposide since its long-term administration is feasible and its activity has been demonstrated in various tumors, including NSCLC $[17,41]$. The results of the present phase II study of this dose-intense regimen in advanced NSCLC are reported herein.

\section{Patients and methods}

Patients

Patients with histologically proven NSCLC of locally advanced disease stage III a or IIIb [26] or with distant metastases were entered in this study. Further eligibility criteria included a measurable lesion, a WHO performance status of 2 or better, a WBC of $>3.0 \times 109 / 1$, a platelet count of $>100 \times 109 / 1$, creatinine clearance of $>60 \mathrm{ml} / \mathrm{min}$, and a serum bilirubin level of $<25 \mu \mathrm{mol} / \mathrm{l}$. Before the start of the treatment all patients had a full medical history and physical examination an ECG, a chest X-ray, computerized tomography (CT) of the chest and upper abdomen with and without i.v. contrast, and, if appropriate, clinical measurement of pathological lymph nodes or skin metastases. All patients underwent a neurological examination before the start of and after the completion of the cisplatin treatment and every 3 months thereafter.

During treatment, patients underwent a weekly physical examination; assessment of toxicity; full blood counts; determination of serum electrolyte, calcium, magnesium, and creatinine levels; liver-function tests; and determination of creatinine clearance. The response to treatment was assessed at 2 weeks after the last cisplatin administration. Standard WHO criteria were used for evaluation of response and toxicity [42].

\section{Treatment schedule}

Cisplatin was infused at a dose of $70 \mathrm{mg} / \mathrm{m}^{2}$ on days $1,8,15$, and days 29,36 and 43. Oral etoposide was given at a dose of $50 \mathrm{mg}$ daily on days $1-15$ and 29-43. During the cisplatin administration, patients were hospitalized for $24 \mathrm{~h}$. The treatment regimen consisted of prehydration with $1000 \mathrm{ml}$ dextrose-saline $+20 \mathrm{mmol} \mathrm{KCL}+1 \mathrm{~g}$ $\mathrm{MgSO}_{4}$ over $4 \mathrm{~h}$. Cisplatin powder was dissolved in $250 \mathrm{ml} 3 \% \mathrm{NaCl}$ and infused over $3 \mathrm{~h}$, after which posthydration with 21 dextrose-saline $+40 \mathrm{mmol} \mathrm{KCl}+2 \mathrm{~g} \mathrm{MgSO}_{4}$ was carried out over $8 \mathrm{~h}$. As an antiemetic regimen, $8 \mathrm{mg}$ ondansetron $+10 \mathrm{mg}$ dexamethasone was given as a slow i.v. bolus directly before the start of the cisplatin infusion, and this treatment was repeated if necessary after $12 \mathrm{~h}$. For delayed nausea and vomiting, metoclopramide was given at $20 \mathrm{mg}$ t.i.d. orally or per suppository. Dose reductions were not allowed. If at the day of planned cisplatin administration the WBC was $<2.5 \times 10^{9} / 1$ and/or the platelet count was $<75 \times 10^{9} / 1$, treatment was postponed until recovery to levels above these values, with the maximal delay being 2 weeks. In the case of a delay of $>2$ weeks or in the case of development of neuro- or nephrotoxicity of grade 2 , patients had to be taken off study.

Patients responding to the treatment or showing stable disease at the first response evaluation were continued on treatment with oral etoposide at a dose of $50 \mathrm{mg} / \mathrm{m}^{2}$ on days $1-21$ every 28 days for a maximum of four cycles. Etoposide was given as 50-mg soft gelatin capsules, and the dose was adjusted such that the dose delivered per treatment cycle deviated $<5 \%$ from the planned dose. During the treatment with oral etoposide, patients underwent full blood counts every 2 weeks and determination of serum electrolytes as well as liverand renal-function tests every 4 weeks. Tumor response was evaluated every 8 weeks.

\section{Results}

A total of 54 patients were registered in the study. One patient was considered ineligible because of small-cell histology. Three patients were considered nonevaluable for response: one patient never started treatment, one patient had a protocol violation (too low a cisplatin dose), and one patient had concomitant radiotherapy on the indicator lesion. In all, 15 patients did not complete the planned treatment: 6 patients developed progressive disease, 2 patients had a treatment delay of $>2$ weeks due to leukocytopenia, 2 patients refused further treatment ( 1 after the first and 1 after the fourth cisplatin administration), 1 patient died of a myocardial infarction, 1 patient was taken off study because of the development of tinnitus after the second cisplatin cycle, 1 patient developed neutropenic fever, 1 patient had erysipelas, and 1 patient developed reversible cortical blindness after the fifth cisplatin cycle. These patients were considered treatment failures in the response analysis. Thus, 50 patients were evaluable for response and 47 , for toxicity analysis. The patients' demographics are shown in Table 1.

The 53 eligible patients received a total of 264 administrations of cisplatin, with the median being 6/patient (range 0-6/patient). Reasons why the six planned cisplatin administrations were not completed are shown in Table 2. Treatment delays of 1 week in 14 patients and of 2 weeks in 7 patients were necessary because of slow recovery of leukocytes and/or platelets. With the exception of the patient who developed neutropenic fever, leuko- and thrombocytopenia were not observed before the third cisplatin administration. Of the 35 patients who completed the planned treatment, 17 reached the planned cisplatin dose intensity of $60 \mathrm{mg} / \mathrm{m}^{2}$ per week; 11 patients treated with a 1 -week delay reached a dose intensity of $52.5 \mathrm{mg} / \mathrm{m}^{2}$ per week; and 7 patients treated with a 2-week delay achieved a

Table 1 Patients' characteristics

\begin{tabular}{lc}
\hline Eligible patients $(n)$ & 53 \\
M:F & $40: 13$ \\
Median age (range) & $56(32-70)$ years \\
Performance status (ECOG): & \\
$\quad 0$ & 18 \\
1 & 29 \\
2 & 6 \\
Stage: & \\
III a & 5 \\
$\quad$ IIIb & 17 \\
$\quad$ IV & 31 \\
Previous therapy: & \\
$\quad$ Radiotherapy & 10 \\
$\quad$ Surgery & 3 \\
$\quad$ Radiotherapy + surgery & 3 \\
Histology: & \\
$\quad$ Squamous-cell carcinoma & 23 \\
$\quad$ Adenocarcinoma & 22 \\
$\quad$ Large-cell undifferentiated carcinoma & 8 \\
\hline
\end{tabular}


Table 2 Reasons why the planned treatment was not completed ( $P D$ Progressive disease)

\begin{tabular}{lll}
\hline $\begin{array}{l}\text { Number of CDDP } \\
\text { administrations }\end{array}$ & & Reason off study \\
\hline 0 & 1 patient & Never started \\
1 & 3 patients & $\begin{array}{l}\text { Refusal 1, irradiation on indicator } \\
\text { lesion 1, early PD 1 }\end{array}$ \\
2 & 2 patients & $\begin{array}{l}\text { Neutropenic fever 1, ototoxicity 1 } \\
\text { PD 3, cardiac death 1, } \\
3\end{array}$ \\
6 patients & $\begin{array}{l}\text { ototoxicity 1, }>2 \text {-week delay 1 } \\
\text { Refusal }\end{array}$ \\
5 & 5 patients & $\begin{array}{l}\text { PD 2, cerebral toxicity 1, } \\
>2 \text {-week delay 1, erysipelas 1 }\end{array}$ \\
6 & 35 patients & - \\
\hline
\end{tabular}

dose intensity of $47 \mathrm{mg} / \mathrm{m}^{2}$ per week. In all, 31 patients continued taking oral etoposide after the first response evaluation: 1 patient for 1 course, 10 patients for 2 courses, 4 patients for 3 courses, and 15 patients for the full 4 courses. In 14 cases, etoposide cycles were delayed once or twice for 1 week because of leukocytopenia.

\section{Response}

Of the 22 patients with stage III disease, 21 were evaluable for response; 1 patient was not evaluable because of concomitant radiotherapy. In eight stage III patients the response was not confirmed after 4 weeks because of additional surgery or radiotherapy. Five patients with stage III a tumors were included in this study: in two patients the tumors were considered initially too large for surgery, two patients were considered inoperable for medical reasons, and one patient refused surgery. All five patients with stage III a tumors responded, and two patients underwent a pneumonectomy. Both of the latter patients had viable tumor in the surgical specimen; one patient died of respiratory failure postoperatively and the other patient is alive and free of disease at 220-weeks. Two patients had radiotherapy but their disease relapsed at 21 and 36 weeks, respectively, and one patient refused further treatment. Of the 17 stage III b patients, 13 completed treatment and 6 had a partial response. Including as treatment failures the four patients who refused or did not complete treatment due to toxicity the overall response rate in stage III disease was $52 \%$ (95\% confidence interval $32-77 \%$ ) as opposed to only $35 \%$ in patients with stage IIIb disease $(95 \%$ confidence interval $20-54 \%$ ). Four stage III b patients did not continue taking oral etoposide because of radiotherapy. The other patients were continued on oral etoposide. The overall median duration of survival for all stage III patients was 48 weeks (range 7-220-weeks); the median duration of survival for the subgroup of III b patients was 34 weeks (range 27-61 weeks).
Of the 31 patients with stage IV disease, 29 were evaluable for response. Two patients were not evaluable: one patient never started treatment and one patient received too low a cisplatin dose. Nine patients showed a partial response $(32 \%$; $95 \%$ confidence interval $15-49 \%)$ with a median duration of 28 weeks (range 16-44 weeks). In all, 12 patients showed stable disease with a median duration of 18 weeks (range 12-32 weeks). The median overall duration of survival for stage IV patients was 45 weeks (range 26-106 weeks). The chance of achieving a response was equal for the histologic subtypes; of 21 evaluable patients with squamous-cell carcinoma, 12 showed a response versus $6 / 18$ patients with adenocarcinoma and $2 / 7$ patients with large-cell undifferentiated carcinoma $(P=0.29$; Fisher's exact test). None of the patients with a performance status of 2 (all of whom had metastatic disease) responded.

\section{Toxicity}

The toxicity data are summarized in Table 3. The worst toxicity per patient observed over the whole treatment period is shown according to WHO grade. For ototoxicity the Common Toxicity Criteria (CTC) grading scale was used [27]. Anemia was universal, with 38 patients developing $>$ grade 1 anemia. A total of 30 patients required packed-red-cell transfusions for a total of 127 units. Grade $3+4$ leukocytopenia was observed in 17 patients. Leukocytopenia was the main cause of treatment delay, mainly occurring on day 29 , when the fourth cisplatin administration was planned. Only one patient developed neutropenic fever. There was no toxic death. Thrombocytopenia of grade 3 was observed in six patients and that of grade 4 , in two patients. One patient required a platelet transfusion on one occasion. No hemorrhagic complication was observed.

All patients developed alopecia; nausea and vomiting was seldom observed during the first 3 weeks of the treatment but occurred frequently thereafter and was also frequently reported during the oral etoposide maintenance phase. A total of 20 patients lost $>5 \%$ of their initial body weight, and 5 of these patients showed a weight loss of $>10 \%$. Nephrotoxicity was limited to grade 1 in seven patients. With the exception of the patient who developed

Table 3 Toxicity according to WHO grade: worst toxicity per patient (CTC Common Toxicity Criteria)

\begin{tabular}{lcrrrl}
\hline Toxicity & \multicolumn{4}{l}{ WHO grade } & \\
\cline { 2 - 6 } & 0 & 1 & 2 & 3 & 4 \\
\hline Anemia & 0 & 9 & 31 & 7 & 0 \\
WBC & 4 & 12 & 14 & 13 & 4 \\
Platelets & 13 & 19 & 7 & 6 & 2 \\
Nephrotoxicity & 40 & 7 & 0 & 0 & 0 \\
Neurotoxicity & 33 & 13 & 0 & 0 & $1^{\mathrm{a}}$ \\
Ototoxicity (CTC) & 25 & 8 & 12 & 2 & 0 \\
\hline
\end{tabular}

a Patient with reversible cortical blindness 
reversible cortical blindness, neurotoxicity was limited to grade 1 in 13 patients. In all, 2 patients reported clinical hearing loss (CTC grade 3) and 12 patients, tinnitus (ototoxicity of grade 2). Hypomagnesemia of $<0.55$ $\mathrm{mmol} / \mathrm{l}$ was observed in ten patients. One patient developed seizures after the sixth cisplatin administration, showing a magnesium level of $0.23 \mathrm{mmol} / \mathrm{l}$.

\section{Discussion}

Numerous phase II and III studies have been performed in NSCLC over the last two decades and, nevertheless the discussion on "the best" regimen continues. The combination of cisplatin and etoposide is frequently used, and the response rate averages $30 \%$ [22]. Studies analyzing the results obtained in locally advanced disease separately report even higher response rates of up to $69 \%$ in this subset of patients [39].

Retrospective analyses of several tumor types have suggested that the dose intensity of chemotherapy may be important [8, 20]. However, the results of prospective randomized studies addressing cisplatin dose intensity in NSCLC are inconclusive. The first study was reported in 1981 by Gralla et al. [16]. In this study cisplatin at $120 \mathrm{mg} /$ $\mathrm{m}^{2}$ was compared with cisplatin at $60 \mathrm{mg} / \mathrm{m}^{2}$, given every 4 weeks in combination with vindesine. The response rate was equal in the two arms (43\%), but the response duration was superior in the high-dose arm as compared with the low-dose arm (12 versus 5.5 months) and the median survival of responders in the high-dose arm was more than double that of responders in the low-dose arm [16]. Klastersky et al. [23] compared cisplatin given at 120 versus $60 \mathrm{mg} / \mathrm{m}^{2}$ in combination with etoposide every 3-4 weeks and observed no difference in response rate or survival between the two treatment arms.

In the three-arm study of Gandara et al. [14], cisplatin given as a single agent at $50 \mathrm{mg} / \mathrm{m}^{2}$ on days 1 and 8 every 4 weeks was compared with single-agent high-dose cisplatin given at $100 \mathrm{mg} / \mathrm{m}^{2}$ on days 1 and 8 versus cisplatin given at $100 \mathrm{mg} / \mathrm{m}^{2}$ on days 1 and 8 plus mitomycin $\mathrm{C}$ given at $8 \mathrm{mg} / \mathrm{m}^{2}$ on day 1 every 4 weeks. Only stage IV patients were included in this study. A response was observed in $12 \%$ of patients in the standard-dose arm and in $14 \%$ of those in the high-dose single-agent-cisplatin arm. In the high-dose arm with mitomycin $\mathrm{C}$ the response rate was $27 \%$. Complete responders were observed only in the high-dose arms. Survival, however, did not differ between the treatment arms. The highest cisplatin dose intensity reached in these studies was $41 \mathrm{mg} / \mathrm{m}^{2}$ per week [14].

In a phase 1 study we have shown that with weekly administration of cisplatin a higher cisplatin dose intensity can be reached [33]. Weekly administration of chemotherapy also has the theoretical advantage that regrowth of sublethally damaged tumor cells should be hindered more effectively than in schedules with longer intervals. Studies performed in the 1970s with weekly administration of cisplatin showed activity in NSCLC and head and neck cancer but were not explored further because of toxicity [5, $34,40]$. With improved supportive measures, weekly administration of cisplatin has become feasible, which the present study again confirms: most patients reached a cisplatin dose intensity of $52.5-60 \mathrm{mg} / \mathrm{m}^{2}$ per week, and we observed a response in $32 \%$ of patients with stage IV disease and in $52 \%$ of those with stage III disease. This response rate is comparable with that reported for other "high-ranking" regimens [6, 39].

Also as compared with other studies using frequent dosing of cisplatin in NSCLC, the dose intensity we achieved was high. Higano et al. [18] used cisplatin weekly at a dose of $50 \mathrm{mg} / \mathrm{m}^{2}$ in combination with mitomycin $\mathrm{C}$, vinblastine, and fluorouracil and reported a response in $23 \%$ of their patients, but these included only patients with distant metastases. The median dose intensity of cisplatin reached in their study was $40-44 \mathrm{mg} / \mathrm{m}^{2}$ per week [18]. O'Dwyer et al. [30] reported a phase II study of weekly cisplatin given at a dose of $30 \mathrm{mg} / \mathrm{m}^{2}$ in combination with weekly 24-h infusions of fluorouracil and vinblastine. In all, $44 \%$ of their patients responded; however, the median duration of response was only 4 months [30].

In general, the toxicity of our regimen was acceptable. Only one patient had neutropenic fever; there was no toxic death. Leukocytopenia and, to a lesser degree, thrombocytopenia were the most frequent causes of treatment delay, partly jeopardizing the dose-intensity concept. Only seven patients developed renal toxicity of grade 1; this low number may be related to the administration of cisplatin in hypertonic saline and to the vigorous hydration program. In Higano et al.'s study [18], which also involved cisplatin administration in hypertonic saline, renal toxicity of grade 2 and higher was observed in only 6 of 77 patients. These results contrast with those of Vogl et al. [40], who reported renal toxicity in $40 \%$ of 30 patients treated with cisplatin at $75 \mathrm{mg} / \mathrm{m}^{2}$ on days $1,8,15$ and every 3 weeks thereafter, with cisplatin being infused in dextrose-saline.

In all, 13 patients in our study developed neurotoxicity of grade 1; no patient developed grade 2 neurotoxicity, although most patients received a cumulative cisplatin dose of $420 \mathrm{mg} / \mathrm{m}^{2}$. All these patients were followed for 6 months, if possible, as it is known that neurotoxic signs may even worsen after the cessation of treatment [19]. Cortical blindness is a very seldom-reported manifestation of cisplatin neurotoxicity; a relationship to hypomagnesemia has been suggested [15]. Hypomagnesemia can lead to focal or generalized seizures, as we observed in another patient. However, on the day of visual loss, our patient had a normal serum magnesium level; he recovered completely. Ototoxicity of grade $2+3$ was observed in $28 \%$ of our patients; this toxicity is common to high-dose cisplatin regimens. Kim et al. [21] used cisplatin at $180 \mathrm{mg} / \mathrm{m}^{2}$ every 2 weeks in combination with sodium thiosulfate, thereby achieving a median cisplatin dose intensity of $79 \mathrm{mg} / \mathrm{m}^{2}$ per week, and reported the development of a hearing loss in 9 of 19 patients. Gandara et al. [14] reported a $17 \%$ incidence of ototoxicity in the high-dose cisplatin arm of their study. As clinical hearing loss is irreversible, it now replaces classic cisplatin-induced toxicities such as 
nephro- and gastrointestinal toxicity in being dose-limiting. The response rate of $52 \%$ obtained in stage III disease, in our opinion, warrants further exploration of the present regimen in locally advanced NSCLC, and its combination with radiotherapy might be attractive provided that toxicity can be limited. Recently the Radiation Therapy Oncology Group [24] reported a study of cisplatin given at $50 \mathrm{mg} / \mathrm{m}^{2}$ on days 1 and 8 in combination with oral etoposide given at 75 or $100 \mathrm{mg} /$ day on days $1-14$ with concomitant hyperfractionated radiotherapy. The response rate of $70 \%$ was encouraging, but the toxicity, especially hematologic toxicity and esophagitis, was high [24]. Combination with chemoprotective agents (such as WR-2721 or sodium thiosulfate) could be of interest for these high-dose schedules. If they indeed have a protective effect against toxicity, randomized studies comparing highly dose-intensive regimens with standard-dose regimens in larger patient populations or their combination with radiotherapy would become possible. However, in our opinion, equal treatment results can be achieved in stage IV disease with less intense regimens.

\section{References}

1. Anderson G, Peel ET, Cheong CMB, Broderick NJ (1982) Etoposide - an effective single drug for treating bronchogenic carcinoma. Clin Oncol 8: 215

2. Bhuchar VK, Lanzotti VJ (1982) High-dose cisplatin for lung cancer. Cancer Treat Rep 66: 375

3. Britell JC, Eagan RT, Ingle JN, Creagan ET, Rubin J, Frytak S (1978) cis-Dichlorodiammineplatinum(II) alone followed by adriamycin plus cyclophosphamide at progression versus cisdichlorodiammineplatinum(II), adriamycin and cyclophosphamide in combination for adenocarcinoma of the lung. Cancer Treat Rep 62: 1207

4. Casper ES, Gralla RJ, Kelsen DP, Cvitkovic E, Golbey RB (1979) Phase II study of high-dose cis-dichlorodiammineplatinum(II) in the treatment of non-small cell lung cancer. Cancer Treat Rep 63: 2107

5. Corder MP, Elliot TE, Bell SJ (1977) Dose limiting myelotoxicity in absence of significant nephrotoxicity with a weekly out-patient schedule of cis-platinum(II)diamminechloride. J Clin Hematol Oncol 7: 645

6. Crinò L, Clerici M, Figoli F, Carlini P, Ceci G, Cortesi E, Carpi A, Santini A, Di Costanzo F, Boni C, Meacci M, Corgna E, Darwish S, Scarcella L, Santuci A, Ballatori E, Tonato M (1995) Chemotherapy of advanced non-small cell lung cancer. A comparison of three active regimens. A randomized trial of the Italian Oncology Group for Clinical Research (GOIRC). Ann Oncol 6: 347

7. De Jager R, Longeval E, Klastersky J (1980) High-dose cisplatin with fluid and mannitol-induced diuresis in advanced lung cancer: a phase II clinical trial of the EORTC Lung Cancer Working Party. Cancer Treat Rep 64: 1341

8. Dodwell DJ, Gurney H, Thatcher N (1990) Dose intensity in cancer therapy. Br J Cancer 61: 789

9. Donnadieu N, Paesmans M, Sculier JP (1991) Chemotherapy of non-small cell lung cancer according to disease extent: a metaanalysis of the literature. Lung Cancer 7: 243

10. Eagan RT, Ingle JN, Creagan ET, Frytak S, Kvols LK, Rubin S, McMahon RT (1978) VP-16-213 chemotherapy for advanced squamous cell carcinoma and adenocarcinoma of the lung. Cancer Treat Rep 62: 843
11. Falkson G, Dyk JJ van, Eden EB van, Van der Merwe AM, Van der Berg JA, Falkson HC (1975) A clinical trial of the oral form of 4' dimethyl-epipodophyllotoxin- $\beta$-D-ethylidene glucoside (NSC 141540, VP 16-213). Cancer 35: 1141

12. Forastiere AA, Takasugi BJ, Baker SR, Wolf GT, Kudla-Hatch V (1987) High-dose cisplatin in advanced head and neck cancer. Cancer Chemother Pharmacol 19: 155

13. Gandara DR, Wold HG, Perez EA, Deisseroth AB, Doroshow J, Myers F, McWhirter K, Hannigan J, DeGregorio MW (1989) Cisplatin dose intensity in non-small cell lung cancer: phase II results of a day 1 and 8 high-dose regimen. J Natl Cancer Inst 81: 790

14. Gandara DR, Crowley J, Livingston RB, Perez EA, Taylor SM, Braun TJ, Natale RB, Balcerzak SP (1993) Evaluation of cisplatin intensity in metastatic non-small cell lung cancer: a phase III study of the South West Oncology Group. J Clin Oncol 11: 873

15. Gelder T van, Geurs P, Kho GS, Dippel DWJ, Vecht ChJ, Splinter TAW (1993) Cortical blindness and seizures following cisplatin treatment: both of epileptic origin? Eur J Cancer 10: 1497

16. Gralla RG, Casper ES, Kelsen DP, Braun DW, Dukeman ME, Martini N, Young CW, Golbey RB (1981) Cisplatin plus vindesine combination chemotherapy for advanced carcinoma of the lung. A randomized trial investigating two dosage schedules. Ann Intern Med 95: 414

17. Greco FA (1993) Chronic etoposide administration: overview of clinical experience. Cancer Treat Rev 19 [Suppl]: 35

18. Higano CS, Crowley J, Livingston RB, Goodwin JW, Barlogie B, Stuckey WJ (1991) A weekly cisplatin-based induction regimen for extensive non-small cell lung cancer. Cancer 67: 2439

19. Hilkens PHE, Planting AST, Burg MEL van der, Moll JWB, Putten WLJ van, Vecht CJ, Bent MJ van den (1994) Clinical course and risk factors of neurotoxicity following cisplatin in an intensive dosing schedule. Eur J Neurol 1: 45

20. Hryniuk WM (1988) The importance of dose intensity in the outcome of chemotherapy. In: De Vita VT, Hellman S, Rosenberg SA (eds) Important advances in oncology. Lippincott, Philadelphia, pp 121-141

21. Kim S, Howell SB, McClay E, Kirmani S, Goel R, Plaxe S, Braly P, Bonetti A (1993) Dose intensification of cisplatin chemotherapy through biweekly administration. Ann Oncol 4: 221

22. Klastersky J (1986) Therapy with cisplatin and etoposide for nonsmall-cell lung cancer. Semin Oncol 13 [Suppl 3]: 104

23. Klastersky J, Sculier JP, Ravez P, Libert P, Michel J, Vandermoten G, Rocmans P, Bonduelle Y, Mairesse M, Michiels T, Thiriaux J, Mommen P, Dalesio O, the EORTC Lung Cancer Working Party (1986) A randomized study comparing a high and a standard dose of cisplatin in combination with etoposide in the treatment of advanced non-small cell lung cancer. J Clin Oncol 4: 1780

24. Lee JS, Scott C, Komaki R, Fossella FV, Dundas GS, McDonald S, Byhardt RW, Curran WJ (1996) Concurrent chemoradiation therapy with oral etoposide and cisplatin for locally advanced inoperable non-small-cell lung cancer: Radiation Therapy Oncology Group Protocol 91-06. J Clin Oncol 14: 1055

25. Mabel JA, Little AD (1979) Therapeutic synergism in murine tumors for combinations of cis-diamminedichloroplatinum with VP 16-213 or BCNU. Proc Am Assoc Cancer Res 20: 230

26. Mountain CF (1986) A new international staging system for lung cancer. Chest 89: 225S

27. National Cancer Institute (1989) Common toxicity criteria. Cancer Therapy Evaluation Program, Division of Cancer Treatment, National Cancer Institute, Bethesda, Maryland

28. Nissen NI, Pajak TF, Leone LA, Bloomfield CD, Kennedy BJ, Ellison RR, Silver RT, Weiss RB, Cuttner J, Falkson G, Kung F, Bergevin PR, Holland JF (1980) Clinical trial of VP 16-213 (NSC $141540)$ iv twice weekly in advanced neoplastic disease. Cancer 45: 232

29. Non-small Cell Lung Cancer Collaborative Group (1995) Chemotherapy in non-small cell lung cancer: a meta-analysis using updated data on individual patients from 52 randomized clinical trials. BMJ 311: 899 
30. O’Dwyer PJ, Langer CJ, Walczak J, Levy MH, Padavic-Shaller K, Hudes GR, Litwin S, Comis RL (1991) Phase II study of weekly 5fluorouracil, cisplatin and vinblastine in advanced non-small cell lung cancer. Eur J Cancer 27: 1589

31. Ozols RF, Ostecha Y, Myers CE, Young RC (1985) High-dose cisplatin in hypertonic saline in refractory ovarian cancer. J Clin Oncol 3: 1246

32. Pannetiere FJ, Vance RB, Stuckey WJ, Coltman CA, Costanzi JJ, Chen TT (1983) Evaluation of single-agent cisplatin in the management of non-small cell carcinoma of the lung: a Southwest Oncology Group study. Cancer Treat Rep 67: 399

33. Planting AST, Burg MEL van der, Boer-Dennert M de, Stoter G, Verweij J (1995) Phase I study of weekly high-dose cisplatin combined with long term oral etoposide in advanced solid tumors. Ann Oncol 6: 190

34. Randolph VL, Wittes RE (1978) Weekly administration of cisdiamminedichloroplatinum(II) without hydration or osmotic diuresis. Eur J Cancer 14: 753

35. Rossof AH, Bearden JD III, Coltman CA (1976) Phase II evaluation of cis-diamminedichloroplatinum(II) in lung cancer. Cancer Treat Rep 60: 1679

36. Ruckdeschel JC (1990) Is chemotherapy for metastatic non-smallcell lung cancer "worth it"? J Clin Oncol 8: 1293
37. Schabel FM, Trader MW, Laster WR, Corbett TH, Griswold DP (1979) cis-Dichlorodiammineplatinum(II): combination chemotherapy and cross-resistance studies with tumors of mice. Cancer Treat Rep 63: 1459

38. Souquet PJ, Chauvin F, Boissel JP, Cellerino R, Cormier Y, Ganz PA, Kaasa S, Pater JL, Quoix E, Rapp E, Tumarello D, Williams J, Woods BL, Bernard JP (1993) Polychemotherapy in advanced non small cell lung cancer: a meta-analysis. Lancet 342: 19

39. Splinter T, Kok T, Kho S, Lameris H, Kate F ten, Dalesio O, Dolman B, Palmen F, Bouvy J, Simonis F, Harper P, Rankin E Reijswoud I van, Hoogenhuijze J van (1986) A multicenter phase II trial of cisplatin and oral etoposide (VP-16) in inoperable nonsmall-cell lung cancer. Semin Oncol 13 [Suppl 3]: 97

40. Vogl SE, Berenzweig M, Camacho F, Greenwald E, Kaplan BH (1982) Efficacy study of intensive cisplatin therapy in advanced non-small cell bronchogenic carcinoma. Cancer 50: 24

41. Waits TM, Johnson DH, Hainsworth JD, Hande KR, Thomas M, Greco FA (1992) Prolonged administration of oral etoposide in non-small cell lung cancer: a phase II trial. J Clin Oncol 10: 292

42. WHO (1979) Handbook for reporting results of cancer treatment. Offset publication 48. WHO, Geneva 